\title{
Neurexin Is Expressed on Nerves, But Not at Nerve Terminals, in the Electric Organ
}

\author{
Anthony B. Russell and Steven S. Carlson \\ Department of Physiology and Biophysics, University of Washington, Seattle, Washington 98195
}

Neurexins are highly variable transmembrane proteins hypothesized to be nerve terminal-specific cell adhesion molecules. As a test of the hypothesis that neurexin is restricted to the nerve terminal, we examined neurexins in the electric organ of the elasmobranch electric fish. Specific antibodies generated against the intracellular domain of electric fish neurexin were used in immunocytochemical and Western blot analyses of the electromotor neurons that innervate the electric organ. Our results indicate that neurexin is not expressed at electric organ nerve terminals, as expected by the neurexin hypothesis. Instead, neurexin is expressed by electromotor neurons and on myelinated axons. This neurexin has a molecular weight of 140
$\mathrm{kDa}$, consistent with an $\alpha$-neurexin. In addition, we find that perineurial cells of the electromotor nerve also express a neurexin. These cells surround bundles of axons to form a diffusion barrier and are thought to be a special form of fibroblast. The results of the study argue against a universal role for neurexins as nerve terminal-specific proteins but suggest that neurexins are involved in axon-Schwann cell and perineurial cell interactions.

Key words: neurexin; electric organ; Torpedo; Narcine; electromotor nucleus; glutathione S-transferase; perineurium, Schwann cell
Neurexins constitute a family of related highly polymorphic proteins, the first of which was identified as the calcium-dependent $\alpha$-latrotoxin receptor (Ushkaryov et al., 1992, Ushkaryov and Südhof, 1993). The $\alpha$-latrotoxin from black widow spider venom induces massive exocytosis of synaptic vesicles from presynaptic neurons (Gorio et al., 1978). There is in vitro evidence suggesting that the cytoplasmic domain of neurexin interacts with the synaptic vesicle protein synaptotagmin (Petrenko et al., 1991; Hata et al., 1993; Perin, 1994) and with proteins believed to be a part of the docking machinery for vesicles, such as the N-type calcium channel (O'Connor et al., 1993). In the rat CNS, immunocytochemical data suggest that neurexins are localized to the nerve terminal (Geppert et al., 1992; Ushkaryov et al., 1992). The cDNAs for the three neurexin genes from rat and cow CNS have been fully sequenced (Ushkaryov et al., 1992, 1994; Ushkaryov and Südhof, 1993). The extracellular domain of the neurexin protein has homology to several extracellular matrix (ECM) molecules, such as laminin, agrin, and heparan sulfate proteoglycan (Ushkaryov et al., 1992), suggesting a possible extracellular adhe-

\footnotetext{
Received March 3, 1997; revised April 1, 1997; accepted April 9, 1997.

This work was supported by the W. M. Keck Foundation, National Institutes of Health Grant NS 22367, and a NASA Graduate Student Research Program Fellowship (A.B.R.). We thank Lorraine Gibbs for technical assistance with immunocytochemistry experiments and Paulette Bruenner at the W. M. Keck Center for Advanced Studies in Neural Signaling for assistance with confocal microscopy, Kathy Buckley for the D. ommata EMN $\lambda$ gt10 cDNA library, Linda Wordeman for anti-tubulin antibodies, and Bruce Tempel for the GST-potassium channel fusion protein. We also thank Regis Kelly and Mani Ramaswami for assistance in the initiation of this study, Laura Ginkel, Andy Hunter, and Tom Knight for useful discussions, and Linda Wordeman for critical evaluation of this manuscript.

The GenBank accession number for the EMN neurexin cDNA fragment used to construct the pGEX expression vector is U95949.

Parts of this paper were reported previously at the 22nd Society of Neuroscience Meeting, Washington, DC, 1996.

Correspondence should be addressed to Dr. Steven. S. Carlson, Department of Physiology and Biophysics, Mail Code 357290, University of Washington, Seattle, WA 98195.

Copyright (C) 1997 Society for Neuroscience $0270-6474 / 97 / 174734-10 \$ 05.00 / 0$
}

sive function (Petrenko, 1993). The extracellular domain of neurexin exhibits extensive variability because of alternative splicing and the use of alternate promoters in the three genes that encode the various neurexins (Ushkaryov et al., 1992, 1994; Ushkaryov and Südhof, 1993).

The hypothesis has been proposed that neurexins are synapsespecific transmembrane cell adhesion molecules that link a postsynaptic ligand with intracellular exocytotic machinery molecules of the nerve terminal (Geppert et al., 1992). The high variability of neurexin forms could reflect the synaptic complexity of the CNS with specific neurexin-postsynaptic protein interactions found at particular types of synapses acting as a potential neuronal recognition system (Geppert et al., 1992).

However, there are concerns regarding the neurexin hypothesis. Previous immunocytochemical data supporting a nerve terminal localization for neurexin are sparse and limited to two areas of the rat CNS (Geppert et al., 1992, Ushkaryov et al., 1992). Synaptic structures are unaffected in Drosophila mutants lacking neurexin (Baumgartner et al., 1996). The role of neurexin as a physiologically relevant receptor for $\alpha$-latrotoxin has recently been cast in doubt because of the discovery of a calcium-independent $\alpha$-latrotoxin receptor that does not seem to be a neurexin (Davletov et al., 1996, Krasnoperov et al., 1996).

The electric organ from the marine elasmobranch electric ray provides a model to test the neurexin hypothesis. The electric organ is a relatively simple nervous tissue comprising a homogenous population of cholinergic neurons, which synapse on a homogenous population of postsynaptic cells. (Bennet, 1971). The neurons that innervate the electric organ originate from the electromotor nucleus (EMN) in the medulla, which is anatomically separated from the target tissue (Bennet, 1971). Analysis of the electric organ allows examination of neurexin from a single synaptic type. The electric organ provides a rich source of nerve terminals that are readily accessible for biochemical and immunocytochemical study. One expectation of 
the neurexin hypothesis should be that the electric organ contains a single neurexin form or a simple complement of neurexin forms restricted to the nerve terminal.

In this paper, we report that neurexin is not present at nerve terminals but is expressed on myelinated nerves in the elasmobranch electric organ at axon-glial cell boundaries. We also find neurexin to be expressed by non-neuronal perineurial cells. Our data do not support the neurexin hypothesis but suggest an entirely different role for neurexin. Our data suggest that neurexin may be involved in perineurial cell adhesion and axon-glia interactions.

\section{MATERIALS AND METHODS}

PCR cloning and fusion protein generation. Degenerate primers based on the highly conserved $\mathrm{C}$ terminus of rat and cow neurexins (Ushkaryov et al., 1992, 1994; Ushkaryov and Südhof, 1993) were used in PCR techniques to amplify the homologous region of the elasmobranch electric fish (Discopyge ommata) neurexin from an EMN $\lambda$ gt10 cDNA library (a gift from K. Buckley, Harvard University, Cambridge, MA) (Trimble et al., 1988) with a Perkin-Elmer (Norwalk, CT) 9600 thermocycler based on described methods (Sambrook et al., 1989). We used the following primers in the PCR methods: sense primer, GAGAGAGAATTCCTNTAYGCNATGTAYAARTA; antisense primer, GAGAGAGCGGCCGCTTANACRTARTAYTCYTTRTCYTT $(\mathrm{N}=\mathrm{A}, \mathrm{T}, \mathrm{G}$, and $\mathrm{C} ; \mathrm{Y}=$ $\mathrm{C}$ and $\mathrm{T}$; and $\mathrm{R}=\mathrm{A}$ and $\mathrm{G})$. DNA sequencing was performed using a Sequenase autoradiographic sequencing kit (Amersham, Cleveland, $\mathrm{OH}$ ) and a sequencing gel apparatus (Bio-Rad, Hercules, CA). Analyses of DNA sequences were performed with a UNIX-based software package (Wisconsin Package, Genetics Computer Group, Madison, WI). The amplified fragment was subcloned into a glutathione $S$-transferase (GST) expression vector (pGEX-5X, Pharmacia, Piscataway, $\mathrm{NJ}$ ), and the fusion vector was sequenced to verify that the fragment was inserted correctly. The GST-electric fish neurexin fusion protein (GST-neurexin) was expressed at high levels in bacteria and purified according to the suggestions of the manufacturer (Pharmacia). A second expression vector was constructed using the same electric fish neurexin fragment and the maltosebinding protein (MBP) vector (New England Labs, Cambridge, MA). The MBP-electric fish neurexin fusion protein (MBP-neurexin) was expressed in bacteria and purified according to the suggestions of the manufacturer.

Anti-electric fish neurexin antibody production and purification. Rabbits were immunized with purified GST-neurexin fusion protein according to described methods (Harlow and Lane, 1988). The resulting anti-neurexin antibodies were affinity purified using the GST-neurexin fusion protein covalently linked to glutathione-Sepharose resin using dimethylpimelimidate (DMP) as the cross-linking reagent (GST-neurexin resin) (Brew et al., 1975). To accomplish this, the fusion protein was first bound to glutathione-Sepharose resin, and the resin was exposed to $100 \mathrm{~mm}$ DMP, $\mathrm{pH} 8.2$, overnight at $4^{\circ} \mathrm{C}$. After this reaction was complete, the resin was washed repeatedly with $0.2 \mathrm{M}$ HEPES, $\mathrm{pH} 8.2$, and then once with $20 \mathrm{~mm}$ ethanolamine to quench any remaining cross-linking reagent. We washed the resin with $100 \mathrm{~mm} 3$-(cyclohexylamino)-1-propanesulfonic acid, $\mathrm{pH}$ 11.5 , to remove any bound proteins that had not been cross-linked. The fusion protein resin was neutralized with $100 \mathrm{~mm} \mathrm{NaCl}$ and $50 \mathrm{~mm}$ 4-morpholinepropanesulfonic acid, $\mathrm{pH} 6.8$.

Specificity of the antibodies was demonstrated by adsorbing the affinity-purified antibodies with GST-neurexin resin in 5\% bovine serum albumin and testing the adsorption on Western blots of MBP-neurexin. As a control for the adsorption, a GST fusion protein containing a region of the rat potassium channel (a gift from B. Tempel, University of Washington) (Wang et al., 1993) was cross-linked to glutathione-Sepharose resin $\left(\mathrm{GST}_{-} \mathrm{K}^{+}\right.$resin) with $100 \mathrm{~mm}$ DMP. Specific anti-neurexin antibodies were identified as those antibodies blocked by GST-neurexin resin but not by GST-K ${ }^{+}$resin. All Western blots and immunocytochemical experiments were performed with affinity-purified anti-electric fish neurexin antibodies that had been adsorbed with $\mathrm{GST}-\mathrm{K}^{+}$resin to remove anti-GST antibodies.

Immunocytochemistry. Marine elasmobranch electric rays, Torpedo californica (Marinus) or Narcine brasiliensis (Gulf Specimens), were anesthetized as described previously (Carlson et al., 1978). The electric organ, EMN, and electromotor nerve were dissected (See Fig. 1 for schematic representation of the electric fish tissues used in this study) and immersion-fixed in $4 \%$ paraformaldehyde. After cryoprotection, $25 \mu \mathrm{m}$ sections were cut with a cryostat (Reichert-Jung). In some cases, sections

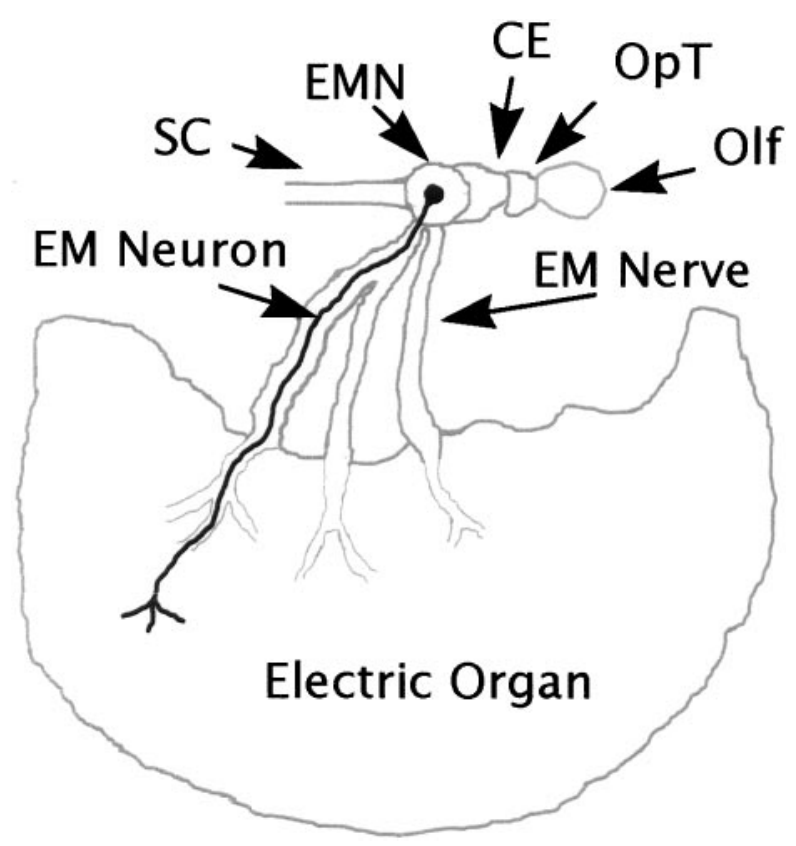

Figure 1. Schematic diagram of the electromotor pathway. Electromotor neurons originate in the EMN and send out processes that synapse on the electrocytes of the electric organ. The collection of axonal processes constitutes the electromotor nerve (EM Nerve). A single electromotor neuron (EM Neuron) is shown as an example of the locations of the neuronal cell body, axonal process, and nerve terminal. The EMN, electromotor nerve, and electric organ tissues were extracted from T. californica and $N$. brasiliensis for this study. All marine elasmobranch electric rays share this electromotor pathway. $S C$, Spinal cord; $C E$, cerebellum; $O p T$, optic tectum; Olf, olfactory lobes. Modified from Bennet (1971). The drawing is for illustrative purposes, and the relative size of the electromotor neuron is not accurate. Only one of the two electric organs is shown for the sake of simplicity.

were incubated in methanol to aid in antibody penetration into the tissue (Hockfield et al., 1993). Sections were labeled with primary antibodies, and bound antibodies were detected using fluorescent secondary antibodies (Jackson Immunochemicals, West Grove, PA) following described methods (Hockfield et al., 1993). Labeled sections were analyzed on a fluorescent confocal microscope (Bio-Rad), and images were collected using an IBM PC computer.

Tissue extractions. The EMN, electromotor nerve, and electric organ were removed from an anesthetized fish as described previously (Carlson et al., 1978). The EMN contains primarily the cell bodies of the electromotor neurons; the electromotor nerve contains the axons of the electromotor neurons; and the electric organ contains the axons and nerve terminals of these neurons (see Fig. 1). The EMN and electromotor nerve were extracted once with $280 \mathrm{~mm} \mathrm{NaCl}, 10 \mathrm{~mm}$ Tris-Cl, pH 7.5 (5× volume per weight of tissue), and protease inhibitors (1 mM diisopropylfluorophosphate, $100 \mu \mathrm{M}$ pepstatin, $100 \mu \mathrm{M}$ leupeptin, and $100 \mu \mathrm{M}$ chyhmostatin). After a $10,000 \times g$ centrifugation for $30 \mathrm{~min}$, the pellets were extracted for $2 \mathrm{hr}$ with $3 \%$ Triton X-100, $280 \mathrm{~mm} \mathrm{NaCl}, 10 \mathrm{~mm}$ Tris-Cl, pH 7.5 (5× volume per weight of original tissue), and protease inhibitors and then centrifuged at $20,000 \times g$ for $10 \mathrm{~min}$. The resulting detergent-resistant pellets were extracted for $2 \mathrm{hr}$ with $8 \mathrm{M}$ urea, $0.5 \%$ Triton X-100, $280 \mathrm{~mm} \mathrm{NaCl}, 10 \mathrm{~mm}$ Tris-Cl, pH $7.5(5 \times$ volume per weight of original tissue), and protease inhibitors and centrifuged at $20,000 \times g$ for 10 min to produce a supernatant. The electric organ was treated according to the method of Godfrey et al. (1984) to prepare an insoluble fraction that is enriched in ECM proteins. This preparation yields an initial salt extract $(400 \mathrm{~mm} \mathrm{NaCl}, 1 \mathrm{~mm}$ EGTA, $1 \mathrm{~mm}$ EDTA, and $10 \mathrm{~mm}$ Tris-Cl, $\mathrm{pH} 7.5$ ) of the electric organ and a detergent extract (3\% Triton X-100 and $10 \mathrm{~mm}$ Tris-Cl, $\mathrm{pH} \mathrm{7.5)} \mathrm{of} \mathrm{the} \mathrm{salt-resistant} \mathrm{pellet.}$ The detergent-resistant pellet was washed with a series of salt buffers (400 to $100 \mathrm{~mm} \mathrm{NaCl}$ buffered with Tris-Cl, $\mathrm{pH} \mathrm{7.5)} \mathrm{before} \mathrm{urea} \mathrm{extrac-}$ tion (8 $\mathrm{m}$ urea, $0.5 \%$ Triton $\mathrm{X}-100$, and $10 \mathrm{~mm}$ Tris-Cl, $\mathrm{pH} 7.5)$. 
A

EMN LYAMYKYRNRDEGSYQVDETRNYISNSAQTNGTVVKEKQPGAKGSNRKHRNKDKEYYV ||||||||||||||||||||||||||||$|:|||::||||::|::::|::||||||||$ $\boldsymbol{R A T}$ LYAMYKYRNRDEGSYQVDETRNYISNSAQSNGTLMKEKQASSKSGHKKQKNKDKEYYV

B

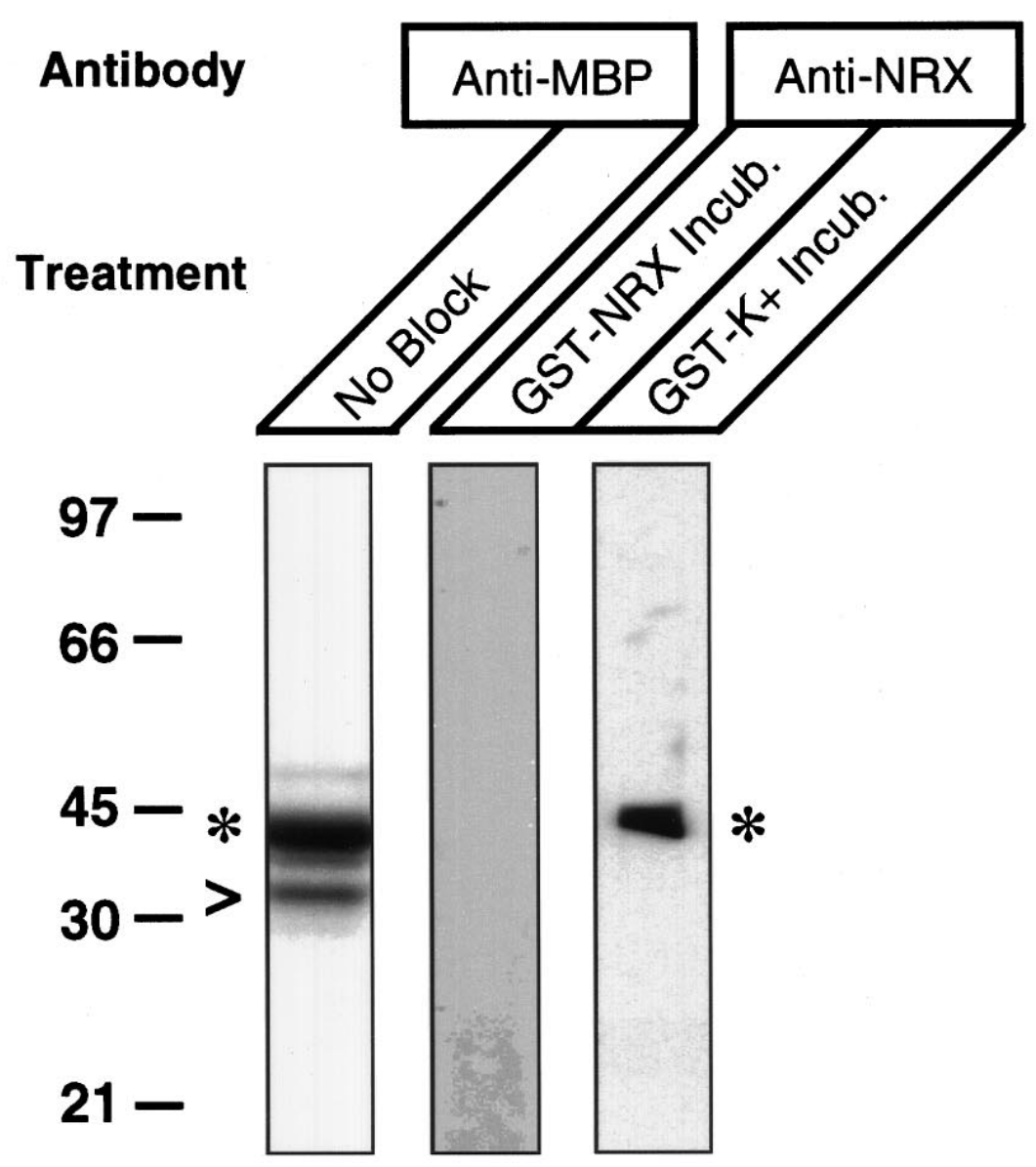

Figure 2. Generation of specific anti-electric fish neurexin antibodies. $A$, Amino acid sequence alignment of electric fish neurexin to rat neurexin III $\alpha$. The amino acid sequence for electric fish neurexin was deduced from an isolated electric fish neurexin cDNA fragment. cDNA encoding the entire cytosolic domain from the end of the transmembrane region to the $\mathrm{C}$ terminus of electric fish neurexin was isolated using PCR amplification from a $D$. ommata elasmobranch electric ray EMN $\lambda$ gt10 cDNA library. With this cDNA fragment, we constructed a GST-neurexin fusion vector, and the resulting purified fusion protein was used to produce antisera in rabbits. Solid lines denote identical amino acids; colons denote conserved amino acid changes. The electric fish neurexin fragment $(E M N)$ is $79 \%$ identical to rat neurexin III $\alpha(R A T)$. $B$, Specificity of the anti-neurexin antibodies. We constructed a second fusion protein, a maltose-binding protein-neurexin with the same cytosolic domain of electric fish neurexin, and subjected the purified protein to SDS-PAGE and immunoblotting procedures. The blotted fusion protein was probed with anti-maltose-binding protein (anti-MBP) antibodies, resulting in a band of the expected molecular mass of $45 \mathrm{kDa}$ (denoted by asterisks). The arrowhead most likely represents a proteolytic cleavage fragment of MBP-neurexin. MBP-neurexin was also probed with affinity-purified anti-electric fish neurexin (anti-NRX) antibodies incubated with a GST-K ${ }^{+}$fusion protein covalently attached to glutathione-Sepharose resin $\left(G S T-K^{+}\right.$Incub.) (See Materials and Methods) or with GST-neurexin similarly attached to glutathione-Sepharose resin (GST-NRX Incub.). For the rest of the study and subsequent experiments, anti-electric fish neurexin antibodies were affinity-purified on GST-neurexin resin, followed with adsorption with GST-K ${ }^{+}$resin to remove antibodies to GST proteins. Numbers on the left represent molecular masses in kilodaltons.

Miscellaneous procedures and reagents. SDS-PAGE and immunoblotting techniques were performed as described (Hockfield et al., 1993). Anti-SV2 monoclonal antibody supernatants (Buckley and Kelly, 1985) were prepared as described (Hockfield et al., 1993). Anti-tubulin antibodies were a kind gift from Dr. L. Wordeman (University of Washington). Anti-maltose-binding protein antibodies were provided by New England Labs, and anti-myelin basic protein antibodies were from Chemicon (Temecula, CA)

\section{RESULTS}

\section{Generation of specific anti-electric fish neurexin antibodies}

To generate antibodies most likely to cross-react with all potential neurexin forms expressed by the EMN neurons that innervate the 


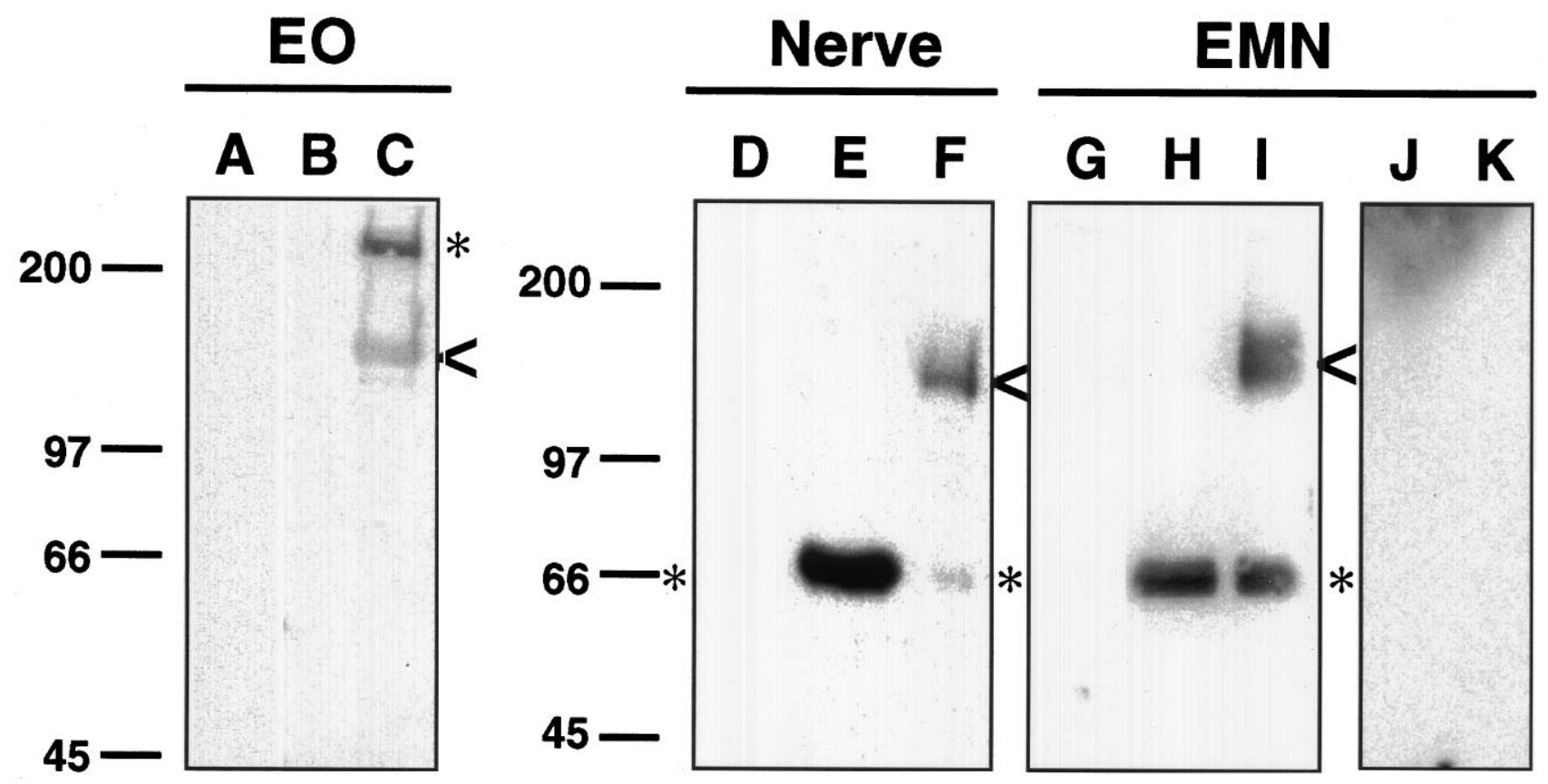

Figure 3. Extraction of neurexins from elasmobranch EMN, electric organ, and electromotor nerve. The electric organ $(E O)$ was extracted according to the method of Godfrey et al. (1984), resulting in an initial buffered $400 \mathrm{~mm} \mathrm{NaCl}$ salt extract of the electric organ (lane A), 3\% Triton X-100 detergent extract of the electric organ (lane B), and an $8 \mathrm{M}$ urea extract of the ECM-rich fraction (See Materials and Methods) (lane C). The EMN and electromotor nerve tissues were extracted with buffered $250 \mathrm{~mm} \mathrm{NaCl}$ salt solution (lanes $D, G$ ), and the resulting pellet was extracted with buffered $3 \%$ Triton X-100 (lanes $E, H, J$ ). The detergent-resistant material was extracted with buffered $8 \mathrm{M}$ urea (lanes $F, I, K$ ). Extracts were separated by SDS-PAGE, immunoblotted, and probed with anti-electric fish neurexin antibodies. A $140 \mathrm{kDa}$ form of neurexin is found to be common to all three tissues (arrowheads) as well as forms of neurexin specific to the tissue source (asterisks). The doublet in lane I may represent neurexin that has not been completely processed by the biosynthetic pathway in the EMN. For lanes $A-I$, the anti-electric fish neurexin antibodies were incubated with GST-K ${ }^{+}$resin to remove antibodies to GST. To demonstrate specificity, the EMN extracts were probed with anti-electric fish neurexin antibodies incubated with GST-neurexin resin (lanes $J, K$ ). Numbers on the left represent molecular masses in kilodaltons.

electric organ, we created a fusion protein containing the intracellular domain of electric fish neurexin to immunize rabbits. The intracellular domain is the most highly conserved region among the known neurexins from rat and cow (Ushkaryov et al., 1992, 1994; Ushkaryov and Südhof, 1993). Antibodies made by other investigators to this domain of rat neurexins recognize all $\alpha$ - and $\beta$-forms derived from the three neurexin genes, except the alternative splice variant of rat neurexin II that results in a unique $\mathrm{C}$ terminus (Ushkaryov et al., 1992). To construct this fusion protein for electric fish neurexins, we first isolated an electric fish cDNA fragment encoding this neurexin domain using degenerate primers based on the highly conserved intracellular sequences of rat and cow neurexins (Ushkaryov et al., 1992, 1994; Ushkaryov and Südhof, 1993) and PCR methods. These procedures allowed us to amplify this cDNA from a D. ommata elasmobranch electric ray EMN $\lambda$ gt10 cDNA library. Analysis of the amino acid sequence deduced from the isolated electric fish neurexin cDNA fragment indicated high homology with all of the neurexins from cow and rat, excluding the unique splice variant of neurexin II, with the highest homology of EMN neurexin with rat neurexin III $\alpha$. EMN neurexin shares $79.7 \%$ identity with rat neurexin III $\alpha$ (Fig. $2 A$ ), $79.3 \%$ identity with rat neurexin $\mathrm{I} \alpha$, and $76.3 \%$ identity with rat neurexin II $\alpha$. The cDNA fragment encoding the entire intracellular domain of electric fish neurexin was subcloned into a GST expression vector, and both strands of the vector were sequenced to verify that the fragment was inserted in the correct orientation and reading frame. After expression in bacteria, the purified fusion protein (GST-neurexin) was used to immunize rabbits.

To affinity purify anti-electric fish neurexin antibodies, GST- neurexin was bound to glutathione-Sepharose beads and then incubated with $100 \mathrm{~mm}$ DMP to cross-link the fusion protein covalently to the resin. After cross-linking of the fusion protein to the glutathione-Sepharose resin, we passed rabbit antisera over the resin, and bound antibodies were eluted by an alkaline $\mathrm{pH}$.

\section{Verifying the specificity of anti-electric fish neurexin antibodies}

To be certain that the affinity-purified anti-electric fish neurexin antibodies were specific to the intracellular fragment of electric fish neurexin, we used a second fusion protein to assay the antibodies. The second fusion protein contained MBP and the same intracellular fragment of electric fish neurexin used to construct GST-neurexin. The second fusion protein (MBP-neurexin) should be recognized only by antibodies to the intracellular fragment of electric fish neurexin and not by anti-GST antibodies. Western blot analysis of purified MBP-neurexin with antimaltose-binding protein antibodies resulted in a band of the expected molecular weight of $45 \mathrm{kDa}$ for the fusion protein (Fig. $2 B$, asterisk). A small amount of the fusion protein seemed to be partially proteolyzed (Fig. $2 B$, arrowhead). The anti-electric fish neurexin antibodies were incubated either with GST-neurexin (GST-NRX) covalently attached to glutathione-Sepharose or with a GST-potassium channel $\left(\mathrm{GST}-\mathrm{K}^{+}\right)$fusion protein similarly attached to glutathione-Sepharose. After incubation with the resins, we used the antibodies to probe MBP-neurexin. We find that exposure of the antibodies with GST-K ${ }^{+}$resin does not block their binding to MBP-neurexin, but incubation with GST-neurexin resin abolishes immunoreactivity (Fig. 2B). Clearly, our anti- 


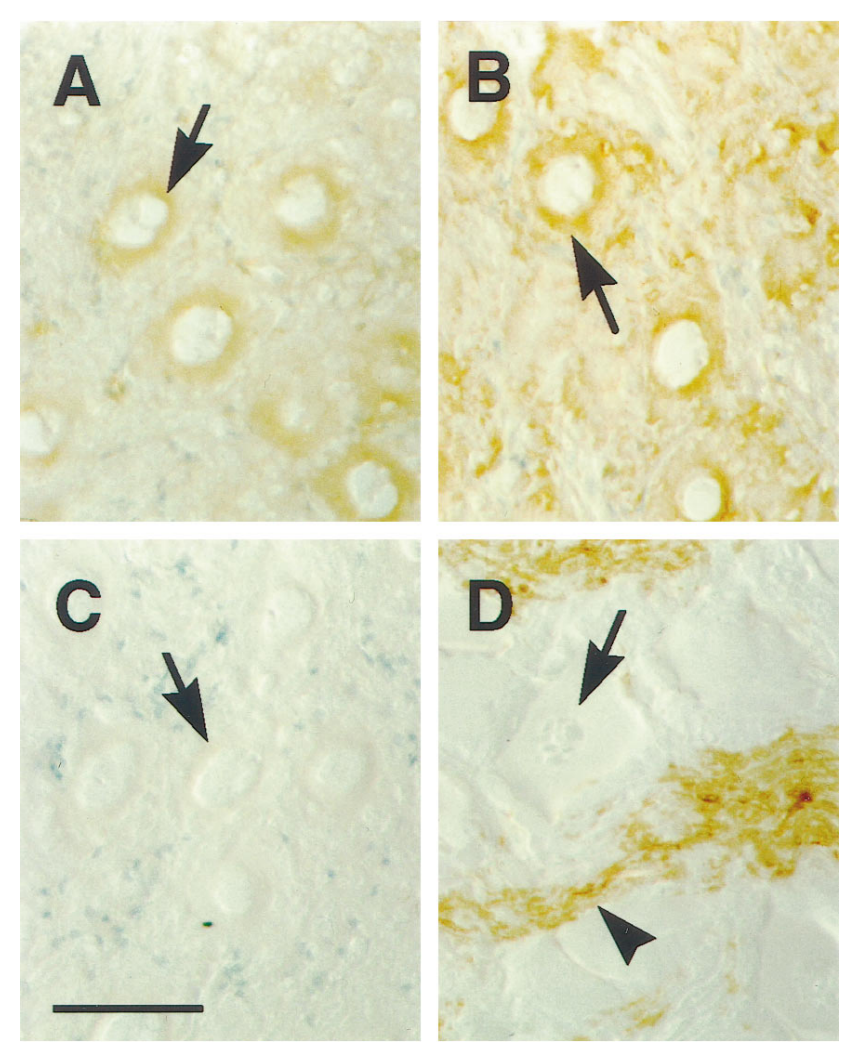

Figure 4. Perinuclear expression of neurexin in EMN neurons. Sections of EMN from elasmobranch were labeled with antibodies to electric fish neurexin $(A)$, the synaptic vesicle protein SV2 $(B)$, myelin basic protein $(D)$, and anti-electric fish neurexin antibodies exposed to GST-neurexin resin $(C)$. Neurexin is expressed in the perinuclear region in EMN neurons $(A$, arrow $)$ in a manner similar to SV2 $(B$, arrow). The perinuclear staining pattern is consistent with Golgi localization, suggesting that the neuronal cell bodies are producing neurexin. Myelin basic protein is not expressed by EMN neurons $(D$, arrow) but is expressed on fibers $(D$, arrowhead). Incubation of electric fish neurexin antibodies with GSTneurexin resin results in the block of perinuclear immunoreactivity $(C$, arrow $)$. Sections were counterstained with methylene green. Scale bar in $C, 50 \mu \mathrm{m}$.

electric fish neurexin antibodies contain immunoreactivity to the C-terminal domain of neurexin, because this immunoreactivity is unaffected by exposure to the GST carrier protein. For all of the experiments reported in this study, anti-electric fish neurexin antibodies were first affinity-purified on GST-neurexin resin and then adsorbed with GST-K ${ }^{+}$resin.

\section{A $140 \mathrm{kDa}$ form of neurexin is common to EMN, electromotor nerve, and electric organ tissues}

To gain an understanding of how many potential forms are expressed by the neurons innervating the electric organ, we extracted neurexins from the elasmobranch EMN, electromotor nerve, and electric organ. The EMN contains the cell bodies and axons of the electromotor neurons, the electromotor nerve contains primarily the axons of the electromotor neurons, and the electric organ contains the axons and nerve terminals of these neurons (Fig. 1). If the electromotor neurons are producing a neurexin and transporting it to the electric organ, it should be found in all three tissues. Salt, detergent, and urea extracts were prepared from the tissues, separated by SDS-PAGE, and analyzed by Western blot using antibodies to electric fish neurexin. Salt extraction is expected to solubilize cytosolic proteins, detergent extraction to solubilize membrane-associated proteins, and urea extraction to solubilize extracellular matrix and cytoskeletal proteins in addition to membrane proteins tightly associated with these proteins (Hockfield et al., 1993). We surveyed all of the extracts by Western blotting and found immunoreactive proteins only in detergent and urea extracts (Fig. 3). These proteins have molecular weights expected for $\beta$-neurexins $(45-66 \mathrm{kDa})$ and $\alpha$-neurexins (150-210 kDa) (Ushkaryov et al., 1992, 1994; Ushkaryov and Südhof, 1993).

We discovered that a form of neurexin with a molecular weight of $140 \mathrm{kDa}$ is common to EMN, electromotor nerve, and electric organ tissues (Fig. 3, lanes $C, F$, I, arrowheads). This localization suggests that the $140 \mathrm{kDa}$ neurexin is the product of the electromotor neurons. This protein requires urea for extraction. The apparent doublet observed in the EMN extract may represent neurexin that has undergone alternative splicing or neurexin that has not been completely processed in the biosynthetic pathway (Fig. 3, lane I). In addition to the $140 \mathrm{kDa}$ form of neurexin, we find neurexins specific to each tissue as well (Fig. 3, asterisks). As a test for the specificity of the anti-electric fish neurexin antibodies and to confirm that the proteins observed are attributable to specific antibody reactivity, we probed a blot of the detergent and urea extracts from the EMN with anti-electric fish neurexin antibodies incubated with GST-neurexin resin (Fig. 3, lanes $J$ and $K$ ). The results show no reactivity, agreeing with our results with MBP-neurexin and confirming specificity of the antibodies. The observed molecular weight of $140 \mathrm{kDa}$ is in agreement with the expected molecular weight for an $\alpha$-neurexin (150-205 kDa) based on published data (Ushkaryov et al., 1992, 1994; Ushkaryov and Südhof, 1993).

\section{The 66 and $210 \mathrm{kDa}$ forms of neurexin}

In addition to the $140 \mathrm{kDa}$ form of neurexin, which is common to the EMN, electromotor nerve, and electric organ, we found another form in the EMN and electromotor nerve and a third form in the electric organ. We observed a $210 \mathrm{kDa}$ form of neurexin in the electric organ that requires urea for extraction (Fig. 3, lane $C$, asterisk). Both the nerve and the EMN express a $66 \mathrm{kDa}$ form of neurexin that requires nondenaturing detergent for extraction, and in the case of the EMN, the $66 \mathrm{kDa}$ form is also extracted with urea (Fig. 3, lanes $E, H$, and $I$, asterisks). A molecular weight of $210 \mathrm{kDa}$ is consistent with an $\alpha$-neurexin $(150-205 \mathrm{kDa})$, and 66 $\mathrm{kDa}$ is consistent with a $\beta$-neurexin $(45-66 \mathrm{kDa}$ ) (Ushkaryov et al., 1992, 1994; Ushkaryov and Südhof, 1993).

\section{Neurexin is expressed by neurons in the EMN}

To verify that electromotor neurons are making a neurexin, we stained cryostat sections of the EMN with our anti-electric fish neurexin antibodies. We find that neurexin immunoreactivity is localized in the perinuclear region of the EMN neurons (Fig. $4 A$, arrow), consistent with a Golgi localization and strongly suggesting that these cells are making neurexin. EMN sections labeled with antibodies to the synaptic vesicle protein SV2 demonstrated a similar perinuclear expression pattern (Fig. 4B, arrow). Labeling of EMN sections with antibodies to myelin basic protein, which is made exclusively by glial cells, resulted in immunoreactivity on fibers within the EMN (Fig. 4D, arrowhead) but no cytoplasmic staining within the neuronal cell (Fig. 4D, arrow). As a test for specificity, the anti-electric fish neurexin antibodies were incubated with GST-neurexin resin, resulting in essentially a complete block of antibody binding (Fig. 4C). 

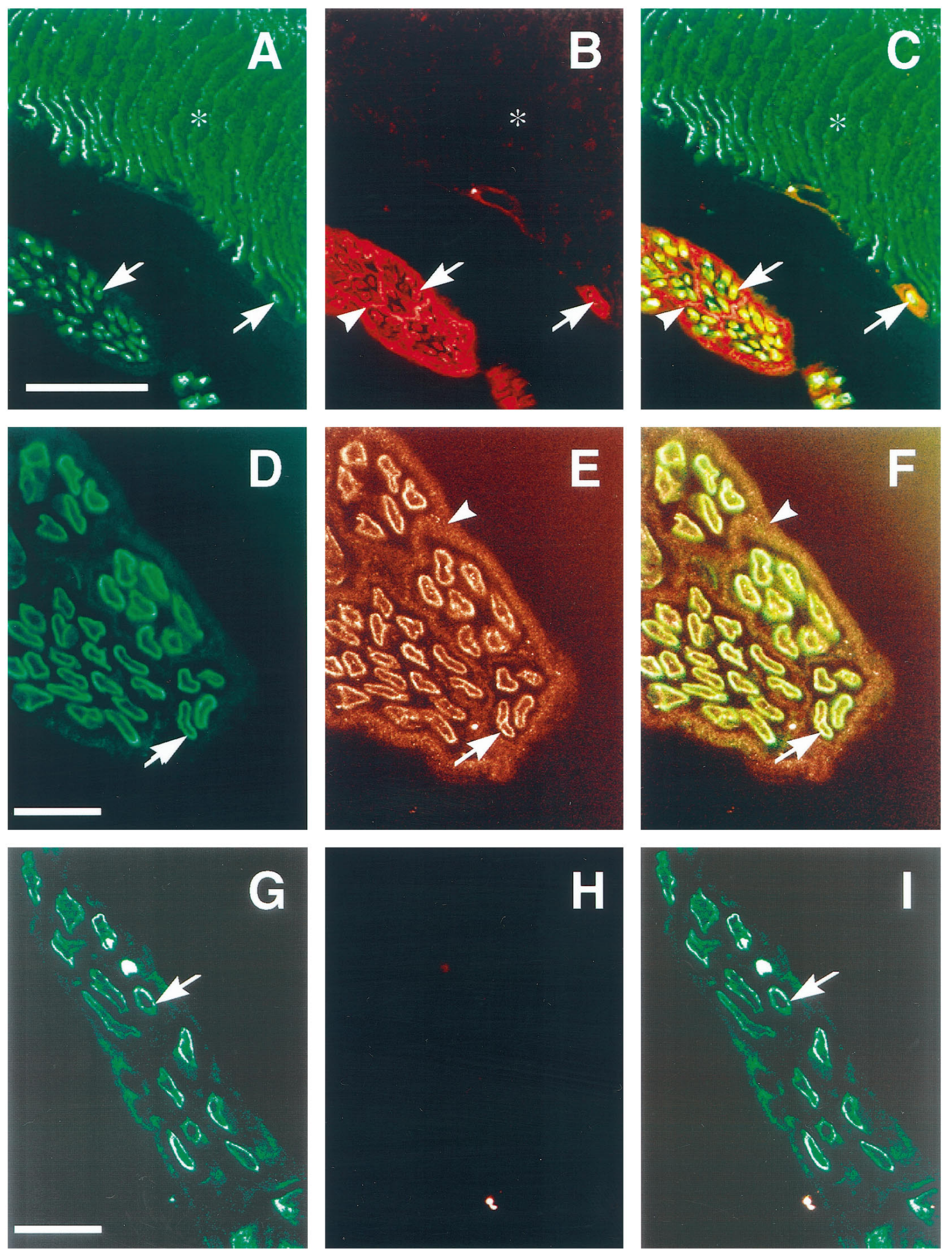

Figure 5. Neurexin is not expressed at nerve terminals, but is expressed on nerves. An electric organ section was double-labeled with a monoclonal antibody to the synaptic vesicle protein SV2 $(A)$ and anti-electric fish neurexin $(B)$. Sections were also labeled with antibodies to myelin basic protein $(D, G)$ and anti-electric fish neurexin $(E, H)$. Images were merged to determine the relative positions of the signals $(C, F, I)$. Bound antibodies were detected with fluorescein anti-mouse $(A)$ or fluorescein anti-rat $(D, G)$ and rhodamine anti-rabbit $(B, E, H)$ antibodies and viewed on a confocal microscope. Neurexin is absent from nerve terminals $(A, B$, asterisks), as labeled by SV2, but is found on nerve fibers $(B$, arrows) and perineurial cells $(B$, arrowhead). SV2 immunoreactivity labels nerve terminals that completely cover the ventral surfaces of the electrocyte $(B$, asterisk). Myelin basic protein immunoreactivity is localized to nerve fibers $(D$, arrow). Neurexin is localized to the nerve fibers $(E$, arrow $)$ and perineurial cells $(E$, arrowhead $)$. Neurexin immunoreactivity on nerve fibers overlaps with myelin basic protein immunoreactivity $(F)$. In $H$, anti-electric fish neurexin antibodies were preincubated with GST-neurexin resin before application to the section. Scale bars: $A, 100 \mu \mathrm{m} ; D, G, 25 \mu \mathrm{m}$. 

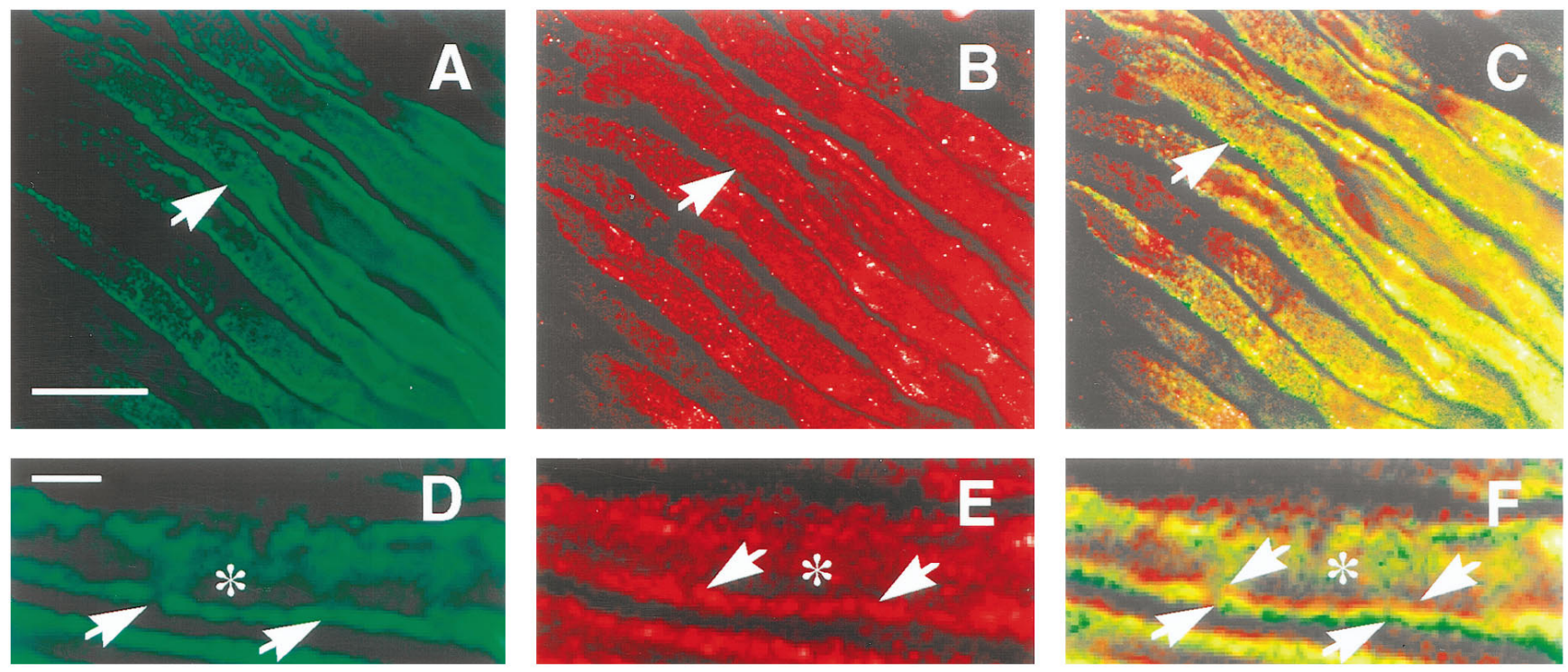

Figure 6. Partial overlap of neurexin and myelin basic protein immunoreactivity on electromotor nerve. Longitudinal sections of electromotor nerve were double-labeled with anti-myelin basic protein $(A, D)$ and anti-electric fish neurexin $(B, E)$ antibodies. Images were merged to determine the relative positions of the signals $(C, F)$. Both antigens are localized to the edge of the nerve fibers (arrows). The neurexin signal is localized interior to the myelin basic protein signal $(D-F$, arrows). As a reference point, the asterisks in $D-F$ mark the axoplasm of the nerve fiber. Myelin basic protein and neurexin seem to overlap partially, presumably because the resolution of the myelin sheath and axonal membrane are near the limit of resolution of the confocal microscope. Scale bars in $B$ and $D, 25 \mu \mathrm{m}$.

\section{Neurexin is not expressed at nerve terminals but is expressed on nerve fibers}

From the neurexin hypothesis, we would expect neurexin to be localized to nerve terminals of electromotor neurons. As a test of the hypothesis, we double-labeled electric organ sections with antibodies to SV2, a synaptic vesicle protein (Buckley and Kelly, 1985), to label nerve terminals and antibodies to electric fish neurexin (Fig. 5A-C). Contrary to expectations, our results show that neurexin is not detected at nerve terminals but is expressed on nerve fibers. Antibodies to SV2 labeled nerve terminals (Fig. $5 A, C$, asterisks) and axons as well (Fig. $5 A, C$, arrows). The nerve terminals completely cover the ventral surfaces of the electrocytes (Bennet, 1971). Anti-neurexin antibodies show strong immunoreactivity on nerve fibers (Fig. 5B, arrow) and perineurial cells (Fig. $5 B$, arrowhead) but no staining at nerve terminals in the same section (Fig. 5B, asterisk). We did not observe any overlap of the $\mathrm{SV} 2$ and neurexin immunoreactive signals on nerve terminals (Fig. 5C).

In an attempt to determine more precisely where neurexin is expressed in the nerve fiber, we double-labeled electric organ sections with antibodies to myelin basic protein and to electric fish neurexin (Fig. 5D-I). Myelin basic protein immunoreactivity is localized to the nerve fiber in the electric organ (Fig. 5D, $G$, arrows). Immunoreactivity for neurexin is also localized to the nerve fiber in the electric organ (Fig. $5 E$, arrow) as well as to perineurial cells (Fig. $5 E$, arrowhead). We observe that neurexin immunoreactivity overlaps with myelin basic protein immunoreactivity on the nerve fibers in the electric organ (Fig. $5 F$, arrow). Incubation of the anti-electric fish neurexin antibodies with GSTneurexin resin resulted in a complete block of immunoreactivity (Fig. $5 H$ ), with no overlapping signal with myelin basic protein immunoreactivity (Fig. 5I), verifying the specificity of the antibody reaction.

The apparent overlap of neurexin immunoreactivity with myelin basic protein immunoreactivity was examined in greater detail by looking at longitudinal sections of the electromotor nerve. We double-labeled longitudinal sections of the electromotor nerve with antibodies to electric fish neurexin and myelin basic protein (Fig. 6). We find the immunoreactive signals not to overlap completely, as should be expected if the axons are expressing neurexin in the nerve fiber (Fig. 6, arrows). When we look more closely at the nerve sections, we find that the signals are separate, with neurexin immunoreactivity interior to myelin basic protein immunoreactivity (Fig. $6 D-F$, arrows). Because the neurons of the electromotor nerve are producing neurexin (Fig. $4 A$ ), and we do not observe neurexin immunoreactivity at nerve terminals, we propose that the EMN neurons produce neurexin destined for axonal membrane localization.

\section{Perineurial cells express neurexin}

In nerves, axon bundles are ensheathed by concentric layers of thin fibroblast-like cells, which constitute the perineurium (Thomas, 1963). These perineurial cells of the electromotor nerves contain neurexin. This is apparent in sections of electric organ double-labeled with antibodies to tubulin and electric fish neurexin (Fig. 7). The anti-tubulin antibodies stain not only the axons (Fig. 7A, $C$, arrowheads) but also the thin layers of fibroblastic cells of the perineurium (Fig. 7A,C, arrows) (Burkel, 1967). These layers of perineurial cells also stain for neurexin immunoreactivity (Fig. 7B,D, arrows). We noticed that detection of neurexin immunoreactivity on the axon was strongest when methanol was used during the tissue section preparation (Fig. 7D). When methanol was excluded, neurexin immunoreactivity was weaker in the axon (Fig. $7 B$ ). This most likely represents a difference in the ability of the anti-neurexin antibodies to penetrate the tissue.

\section{DISCUSSION}

Neurexins are polymorphic transmembrane proteins presumed to be involved in synaptic neuron-neuron interactions. Neurexin is hypothesized to be restricted to the nerve terminal because of the 


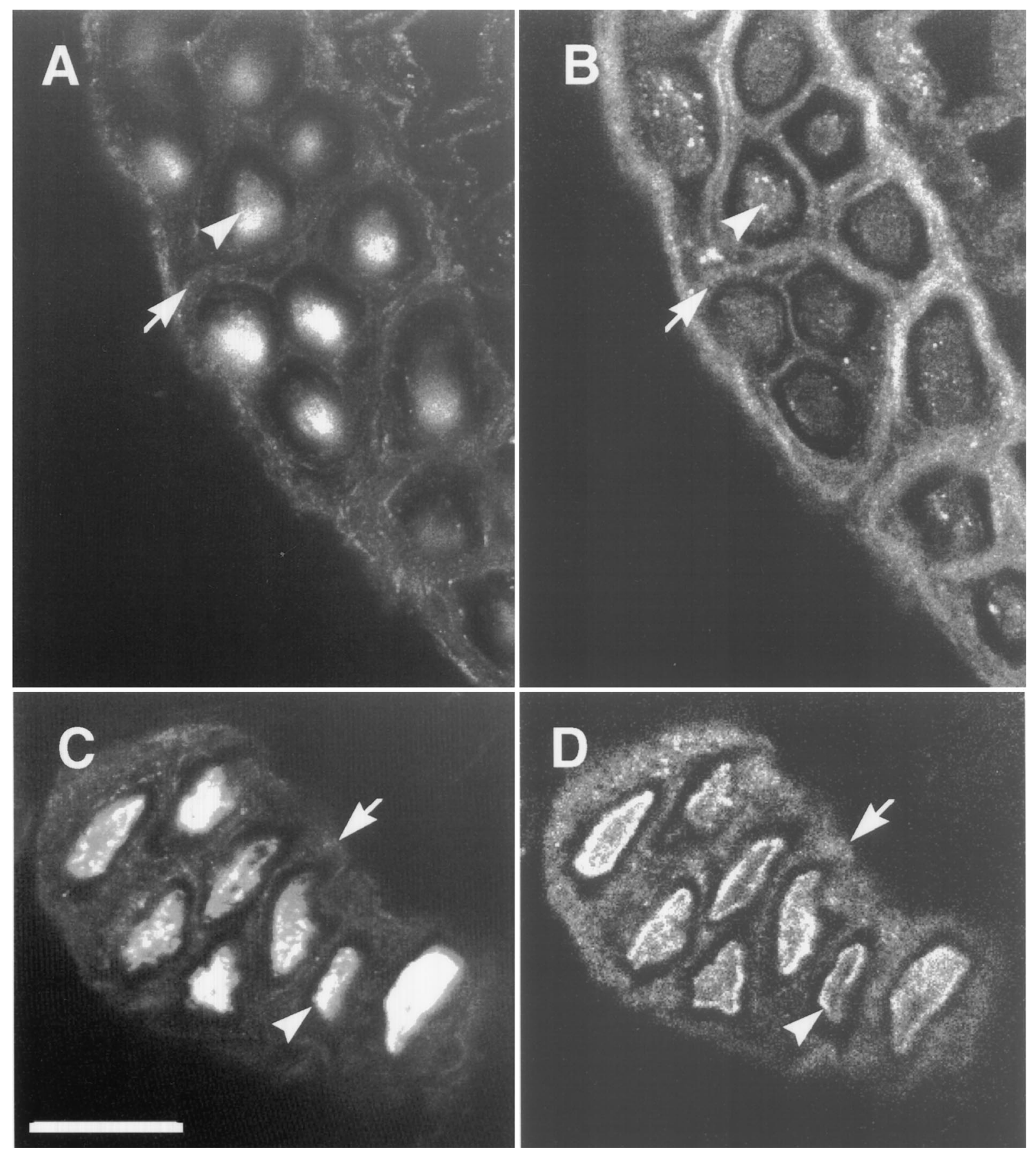

Figure 7. Colocalization of neurexin with tubulin in the perineurium. Electric organ sections were double-labeled with anti-tubulin $(A, C)$ and anti-electric fish neurexin $(B, D)$ antibodies. Both antigens are found in axons (arrowheads) and perineurial cells (arrows). The section in $C$ and $D$ was treated with methanol to increase the signal observed in axons (arrowheads). Methanol treatment presumably increases antibody penetration into the axon. Scale bar in $C, 25 \mu \mathrm{m}$.

ability of the intracellular domain to bind the synaptic vesicle protein synaptotagmin and the immunolocalization to nerve terminals in the rat CNS (Geppert et al., 1992; Ushkaryov et al., 1992; Hata et al., 1993). The extensive variability of the extracellular domain of neurexin is predicted to confer postsynaptic ligand specificity that reflects the synaptic complexity of the CNS. The electric organ from the marine elasmobranch electric ray provides a model to test the hypothesis. The hypothesis would predict that a small complement of neurexin forms would be restricted to the nerve terminal in the electric organ. In contrast, we find that neurexin is not present at nerve terminals. Instead, neurexin is expressed on nerve fibers as well as non-neuronal perineurial cells. We obtained this result with antibodies to the homologous region of fish neurexin, much as previous workers used them in experiments to propose the neurexin hypothesis (Geppert et al., 1992; Ushkaryov et al., 1992). We find a $140 \mathrm{kDa}$ form of neurexin common to the EMN, electromotor nerve, and electric organ, which is presumably expressed on the axons of the EMN cells, 
which are the only cells common in these three tissues. We also find forms of neurexin that are non-neuronal in origin. Thus, our observations do not support the neurexin hypothesis.

Although neurexins may be nerve terminal proteins in the $\mathrm{CNS}$, their absence at electric organ synapses argues against a universal role for neurexin as a nerve terminal protein. Neurexins containing the $\mathrm{C}$ terminus that our antibodies recognize have been detected at CNS nerve terminals, but these variants are not present at peripheral electric organ nerve terminals. Instead, we have detected neurexins on axons and perineurial cells. However, it cannot be ruled out that neurexin variants with unique $\mathrm{C}$ termini that our antibodies are unable to recognize are present at the electric organ synapse. The status of neurexin as a functional component of the exocytotic machinery may have to be reconsidered in light of new evidence. Neurexin was originally isolated as the nerve terminal receptor for $\alpha$-latrotoxin, which causes massive exocytosis (Gorio et al., 1978; Ushkaryov et al., 1992). However, recent studies have reported the isolation of a calcium-independent $\alpha$-latrotoxin receptor that is biochemically distinct from the neurexins (Davletov et al., 1996; Krasnoperov et al., 1996).

Our data suggest that electromotor neurons express an $\alpha$-neurexin but localize it in membranes adjacent to myelin enwrapments of Schwann cells. The evidence is the following: (1) The electromotor neurons seem to be synthesizing a neurexin. Immunocytochemical data show a perinuclear neurexin immunoreactivity in the cell bodies of the electromotor neurons. This localization strongly suggests the presence of neurexin in the Golgi apparatus, which is part of the biosynthetic machinery for plasma membrane proteins and secreted glycoproteins (Alberts et al., 1994). This staining pattern is exactly like that of the synaptic vesicle protein SV2, a known product of electromotor neurons (Scranton et al., 1993; Buckley and Kelly, 1985). (2) Immunocytochemical localization shows neurexin immunoreactivity on axonal membranes, adjacent to the myelin sheath. (3) The tissues that contain the electromotor neurons and their processes, the EMN, the electromotor nerves, and electric organ, also contain the $140 \mathrm{kDa}$ neurexin. These are the major neurons of the EMN and probably the only neurons that the electromotor nerve and electric organ contain (Bennet, 1971). A molecular mass of 140 $\mathrm{kDa}$ is within the range expected for an $\alpha$-neurexin (Ushkaryov et al., 1992; Ushkaryov and Südhof, 1993; Ushkaryov et al., 1994).

In addition to the $140 \mathrm{kDa}$ neurexin, which is common to all tissues of the electromotor pathway, we found two other neurexins: 210 and $66 \mathrm{kDa}$ proteins, most likely $\alpha$ - and $\beta$-neurexins, respectively. We found the $210 \mathrm{kDa}$ protein in the electric organ and the $66 \mathrm{kDa}$ protein in the electromotor nerve, which is located outside of the electric organ, and in the EMN. The origins of these neurexins are unclear, but they are presumably produced by cells other than the electromotor neurons. The $210 \mathrm{kDa}$ protein may be the neurexin produced by the perineurial cells in the nerves inside the electric organ, whereas the $66 \mathrm{kDa}$ neurexin may be made by perineurial cells in the electromotor nerve outside of the electric organ. Perhaps this difference in neurexins might reflect the two different environments of the perineurial cells in the electromotor nerve, especially if neurexin is involved in cell-cell or cell-matrix interactions. Outside the electric organ, the perineurial cells form a layer around the entire nerve bundle. Inside the electric organ, these cells interdigitate into the nerve surrounding bundles of myelinated axons, dividing the nerve into separate cables. This occurs before branch points in the nerve (Terzis and Smith, 1990), and the electromotor nerve only branches inside the electric organ.

We hypothesize a role for neurexin as a cell adhesion protein involved in the formation and maintenance of tight cellular interactions associated with the peripheral nerve and axon bundles. We find neurexin immunoreactivity at the axon-Schwann cell boundary and on perineurial cells that ensheath the nerve. The interaction between perineurial cells and the interaction between axons and Schwann cells share many similarities. The two types of interactions involve a close juxtaposition of membranes to act as a diffusion barrier. Results from electron microscopy studies examining the association of the membranes of the Schwann cell and axon resemble perineurial cell junctions (Burkel, 1967; Little et al., 1995). The Schwann cell forms a barrier around the axon by the tight association of the myelin sheath (Terzis and Smith, 1990). The barrier provided by the tight association of the myelin sheath acts to increase the membrane resistance and to decrease the capacitance associated with the axon (Hille, 1992). The perineurial cells are arranged in concentric layers to form a metabolic diffusion barrier (Burkel, 1967) and to protect the axon from infectious agents (Terzis and Smith, 1990).

Work in Drosophila also suggests that neurexins are involved in the formation of tight cellular junctions. Neurexin has been reported to be involved in septate junction formation in Drosophila (Baumgartner et al., 1996). Septate junctions are formed between glial cells to form a blood-brain barrier around nerves in invertebrates and serve a similar function to that of perineurial cells in vertebrates. Septate junctions fail to form in Drosophila mutants that lack neurexin, resulting in a breakdown of the blood-brain barrier (Baumgartner et al., 1996). It seems that neurexin in the peripheral nerve is involved in the formation of cell-cell interactions that are required for forming specialized barriers.

In this study, we sought to test the neurexin hypothesis that neurexin is localized solely at nerve terminals in the elasmobranch electric organ. Our observations argue against a universal role for neurexins as nerve terminal-specific proteins and suggest a different role for neurexins in the periphery. Our findings suggest that neurexin in the electric organ, rather than being involved in synaptic connectivity, may be involved in perineurial cell adhesion and axon-Schwann cell interactions. Future studies will examine the role of neurexin in axon-Schwann cell interactions during peripheral nerve development.

\section{REFERENCES}

Alberts B, Bray D, Lewis J, Raff M, Roberts K, Watson JD (1994) Molecular biology of the cell. New York: Garland.

Baumgartner S, Littleton JT, Broadie K, Bhat MA, Harbecke R, Lengyel JA, Chiquet-Ehrismann R, Prokop A, Bellen HJ (1996) A Drosophila neurexin is required for septate junction and blood-nerve barrier formation and function. Cell 87:1059-1068.

Bennet MVL (1971) Electric organs. In: Fish physiology (Hoar WS, Randall DJ, eds), pp 347-491. New York: Academic.

Brew K, Shaper JH, Olsen KW, Trayer IP, Hill RL (1975) Cross-linking of the components of lactose synthetase with dimethylpimelimidate. J Biol Chem 250:1434-1444.

Buckley K, Kelly RB (1985) Identification of a transmembrane glycoprotein specific for secretory vesicles of neural and endocrine cells. J Cell Biol 100:1284-1294.

Burkel WE (1967) The histological fine structure of perineurium. Anat Rec 158:177-190.

Carlson SS, Wagner JA, Kelly RB (1978) Purification of synaptic vesicles from elasmobranch electric organ and the use of biophysical criteria to demonstrate purity. Biochemistry 17:1188-1199.

Davletov BA, Shamotienko OG, Lelianova VG, Grishin EV, Ushkaryov YA (1996) Isolation and biochemical characterization of a $\mathrm{Ca}^{2+}$-independent $\alpha$-latrotoxin-binding protein. J Biol Chem 271:23239-23245. 
Geppert M, Ushkaryov YA, Hata Y, Davletov B, Petrenko AG, Südhof TC (1992) Neurexins. Cold Spring Harb Symp Quant Biol 57:483-490.

Godfrey EW, Nitkin RM, Wallace BG, Rubin LL, McMahan UJ (1984) Components of Torpedo electric organ and muscle that cause aggregation of acetylcholine receptors on cultured muscle cells. J Cell Biol 99:615-627.

Gorio A, Rubin LL, Mauro A (1978) Double mode of action of black widow spider venom on frog neuromuscular junction. J Neurocytol 7:193-205.

Harlow E, Lane D (1988) Antibodies: A laboratory manual. Cold Spring Harbor, NY: Cold Spring Harbor.

Hata Y, Davletov B, Petrenko AG, Jahn R, Südhof TC (1993) Interaction of synaptotagmin with the cytoplasmic domains of neurexins. Neuron 10:307-315.

Hille B (1992) Ionic channels of excitable membranes. Sunderland, MA: Sinauer.

Hockfield S, Carlson S, Evans C, Levitt P, Pintar J, Silberstein L (1993) Selected methods for antibody and nucleic acid probes. Cold Spring Harbor, NY: Cold Spring Harbor.

Krasnoperov VG, Beavis R, Chepurny OG, Little AR, Plotnikov AN, Petrenko AG (1996) The calcium-independent receptor of $\alpha$-latrotoxin is not a neurexin. Biochem Biophys Res Commun 227:868-875.

Little GJ, Robinson CS, Heath JW (1995) Cryo-immunogold ultrastructure localization of laminin in adult rat peripheral nerve. J Neurocytol 24:79-84

O'Connor VM, Shamotienko O, Grishin E, Betz H (1993) On the structure of the "synaptosecretosome." Evidence for a neurexin/synaptotag$\min /$ syntaxin $/ \mathrm{Ca}^{2+}$ channel complex. FEBS Lett 326:255-260.

Perin MS (1994) The COOH terminus of synaptotagmin mediates interaction with the neurexins. J Biol Chem 269:8576-8581.
Petrenko AG (1993) $\alpha$-Latrotoxin receptor. Implications in nerve terminal function. FEBS Lett 325:81-85.

Petrenko AG, Perin MS, Davletov BA, Ushkaryov YA, Geppert M, Südhof TC (1991) Binding of synaptotagmin to the $\alpha$-latrotoxin receptor implicates both in synaptic vesicle exocytosis. Nature 353:65-68.

Sambrook J, Fritsch EF, Maniatis T (1989) Molecular cloning: a laboratory manual. Cold Spring Harbor, NY: Cold Spring Harbor.

Scranton TW, Iwata M, Carlson SS (1993) The SV2 protein of synaptic vesicles is a keratan sulfate proteoglycan. J Neurochem 61:29-44.

Terzis JK, Smith KL (1990) The peripheral nerve: structure, function, and reconstruction. New York: Raven.

Thomas PK (1963) The connective tissue of peripheral nerve: an electron microscope study. J Anat 97:35-44.

Trimble WS, Cowan DM, Scheller RH (1988) VAMP-1: a synaptic vesicle-associated integral membrane protein. Proc Natl Acad Sci USA 85:4538-4542.

Ushkaryov YA, Südhof TC (1993) Neurexin III $\alpha$ : extensive alternative splicing generates membrane-bound and soluble forms. Proc Natl Acad Sci USA 90:6410-6414.

Ushkaryov YA, Petrenko AG, Geppert M, Südhof TC (1992) Neurexins: synaptic cell surface proteins related to the $\alpha$-latrotoxin receptor and laminin. Science 257:50-56.

Ushkaryov YA, Hata Y, Ichtchenko K, Moomaw C, Afendis S, Slaughter CA, Südhof TC (1994) Conserved domain structure of $\beta$-neurexins. Unusual cleaved signal sequences in receptor-like neuronal cell-surface proteins. J Biol Chem 269:11987-11992.

Wang H, Kunkel DD, Martin TM, Schwartzkroin PA, Tempel BL (1993) Heteromultimeric $\mathrm{K}^{+}$channels in terminal and juxtaparanodal regions of neurons. Nature 365:75-79. 